\title{
TU/e EmonOWEN

\section{A market-based investigation of large-scale renewable energy integration in northwestern Europe}

\section{Citation for published version (APA):}

Ciupuliga, A. R., Gibescu, M., Pelgrum, E., vd Meijden, M. A. M. M., \& Kling, W. L. (2012). A market-based investigation of large-scale renewable energy integration in northwestern Europe. In X. IEEE (Ed.), Proceedings of the 2012 IEEE Power \& Energy Society General Meeting, 22-26 July 2012, San Diego CA (pp. 1-8). Institute of Electrical and Electronics Engineers. https://doi.org/10.1109/PESGM.2012.6345357

DOI:

10.1109/PESGM.2012.6345357

Document status and date:

Published: 01/01/2012

\section{Document Version:}

Publisher's PDF, also known as Version of Record (includes final page, issue and volume numbers)

\section{Please check the document version of this publication:}

- A submitted manuscript is the version of the article upon submission and before peer-review. There can be important differences between the submitted version and the official published version of record. People interested in the research are advised to contact the author for the final version of the publication, or visit the $\mathrm{DOI}$ to the publisher's website.

- The final author version and the galley proof are versions of the publication after peer review.

- The final published version features the final layout of the paper including the volume, issue and page numbers.

Link to publication

\section{General rights}

Copyright and moral rights for the publications made accessible in the public portal are retained by the authors and/or other copyright owners and it is a condition of accessing publications that users recognise and abide by the legal requirements associated with these rights.

- Users may download and print one copy of any publication from the public portal for the purpose of private study or research.

- You may not further distribute the material or use it for any profit-making activity or commercial gain

- You may freely distribute the URL identifying the publication in the public portal.

If the publication is distributed under the terms of Article 25fa of the Dutch Copyright Act, indicated by the "Taverne" license above, please follow below link for the End User Agreement:

www.tue.nl/taverne

Take down policy

If you believe that this document breaches copyright please contact us at:

openaccess@tue.nl

providing details and we will investigate your claim. 


\title{
A Market-Based Investigation of Large-Scale Renewable Energy Integration in Northwestern Europe
}

\author{
A. R. Ciupuliga, Graduate Student Member, IEEE, M. Gibescu, Member, IEEE, E. Pelgrum, \\ Mart A.M.M. van der Meijden, Member, IEEE and W. L. Kling, senior Member, IEEE
}

\begin{abstract}
A high increase in the installed capacities of Renewable Energy Sources (RES) is expected by 2020 and beyond in Europe, and power systems planners and regulators have to make sure that the power systems are designed and operated to make optimal use of the potential of these clean energy sources.

This paper investigates the consequences of integrating largescale solar and wind power in the future Northwestern European power system. A zonal market model is used, where unit commitment and economic dispatch simulations for a given development scenario of load and generation, including wind power and solar power time series and inter-zonal transmission constraints, are with hourly resolution. The ability of the power system to absorb the available "green" energy is assessed. Moreover, factors that can hamper or improve the RES integration are identified by performing a sensitivity analysis on a subset of the scenario attributes.
\end{abstract}

Index Terms-- power systems, RES integration, strategic planning, solar power, wind power, UC-ED

\section{INTRODUCTION}

$\mathrm{T}_{\mathrm{s}}^{\mathrm{h}, \mathrm{se}}$ he planning of large energy infrastructures in Europe has entered a new dimension, namely the trans-European one. The way of thinking is slowly switching from national to regional (European) interests and challenges, as this is the most efficient way to attain a sustainable energy future. Europe finds itself at the beginning of a transition towards a low carbon and sustainable electricity system, which is guided by the European Union (EU) Energy Policy core objectives: competitiveness, reliability and sustainability [1].

By issuing the EU Directives on Renewable Energy [2] including national renewable targets modified according to economic status, the EU aims towards the 20-20-20 goals presented in the EU Energy and Climate Package (2008). Among those goals is the $20 \%$ share of renewables in the

This work was financially supported by Agentschap.NL under the project North Sea Transnational Grid.

A. R. Ciupuliga, M. Gibescu and M.A.M.M. van der Meijden are with Delft University of Technology, Department of Electrical Sustainable Energy, Group of Power Systems, Mekelweg 4, 2628 CD Delft, The Netherlands (email: A.R.Ciupuliga@tudelft.nl, $\quad$ M.Gibescu@tudelft.nl, M.A.M.M.vanderMeijden@tudelft.nl).

E. Pelgrum is with TenneT TSO B.V. (e-mail: E.Pelgrum@tennet.org,)

W. L. Kling is with Eindhoven University of Technology (e-mail: w.l.kling@tue.nl)
European energy consumption within 2020. As we are approaching 2020, attention starts to shift beyond 2020, towards 2030 and even 2050. According to EWEA's forecast [3], 30\% of EU's electricity will then be produced by wind power. Moreover, the EU prognosis is that the solar power penetration shall increase dramatically to $80 \mathrm{GW}$ by 2020 , and it will continue to grow after 2020. The European Commission (EC) has published in 2011 a roadmap for moving to a competitive low carbon economy in 2050 [7]. There are already studies that suggest that Renewable Energy Sources (RES) could have by 2050 a share in the electricity production varying between $40 \%$ and $100 \%$ [8].

ENTSO-E [5]-[6] together with the EC based on its energy infrastructure package are busy with finding solutions on how to be able to use all the new green energy. Next to them, many studies [9]-[11] were/are busy with the integration of largescale RES in the future power systems.

In the above mentioned context, the purpose of this paper is to investigate the consequences and sensitivities that are related to integrating large-scale solar and wind power in the North-European power system for a 2030 scenario of load, generation and interconnection capacities. Hourly wind and solar power time series are developed and served as an input to the chronological unit commitment and economic dispatch (UC-ED) simulation tool, which is run for a whole year with hourly resolution. The UC-ED is run for a base case and for a few sensitivity scenarios. The ability of the modeled power system to cope with a high RES penetration level is assessed and also factors that might hamper or improve the RES integration are pointed out.

The paper is structured in two main sections and following conclusions. In Section II, the 2030 main scenario and modeling assumptions are presented and the sensitivity scenarios are introduced. Section III focuses on interpreting the results of the UC-ED simulations, including those of the sensitivity analysis. The Conclusions section summarizes the most important findings of the paper.

The main contribution of this paper is to develop a comprehensive range of scenarios for modeling the operation of the 2030 Northwestern European power system and to use them in order to measure the system's ability to integrate large amounts of wind and solar generation. In addition, key aspects in increasing the RES absorption are emphasized. The development of temporally- and spatially-correlated time series for RES production enable accurate assessment of constraints related to the flexibility of fossil-fuel resources, as 
well as of the positive smoothing effect when RES are traded across large geographical areas.

\section{North-WeStern EURope StUdy CASE}

\section{A. Simulations model}

The study case is a future scenario for the year 2030 of load, generation and interconnection capacities for NorthWestern Europe (Fig. 1). The considered countries are Belgium, Denmark, France, Germany, Great Britain, Netherlands, Norway and Sweden. The offshore grid was not explicitly considered, as it was assumed that all the offshore wind is nationally connected by sufficient capacity.

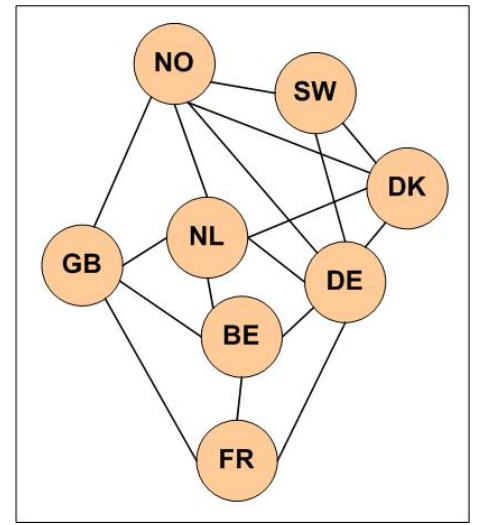

Fig. 1 Transmission corridors in North-Western Europe

For the unit commitment and economic dispatch simulations the commercially available PowrSym 3 model was used [12]. PowrSym3 is a probabilistic, chronological, multiarea, multi-fuel electricity and heat market simulation tool. The UC-ED model is optimized considering sequential hourly time steps (within each weekly horizon), with the purpose of obtaining the minimum operating cost (including fuel, emission and start-up costs) at the system level while the technical constraints for generating units and interconnection capacities are met at all times. The model is run in zonal mode, where only the inter-area transmission capacities allocated to the market are considered, while the networks of different areas are seen as a "copper-plate", hence the underlying physical grid is neglected. The information about different types of power plants technologies, and also about hydro-power plants resource availability for the 8 countries are based on [13], [14]. Biomass was considered only in Germany, and modeled as constant generation.

For the hydro-power plants from Norway and Sweden, a realistic long-range hydro scheduling profile that takes into account seasonal variation was used, as shown in Fig. 2 [14]. The total hydro energy is assumed to be $137.4 \mathrm{TWh}$ for Norway and 65.6 TWh for Sweden. Within the UC-ED simulations, the weekly hydro energy is given as an input, and at the end of the week the unused energy is reported as hydro spill. The hydro stations are the first to be scheduled in the weekly optimization using a price levelling algorithm, which refers to time-related constraints such as generation cost, operational aspects of thermal units and hydro reservoir size. Consequently, the hydro schedule is optimized based on the system's marginal cost, while taking into account reservoir size limits, load prediction and wind power forecasts [15]. Both hydro and RES generation are modeled as having zero generation cost.

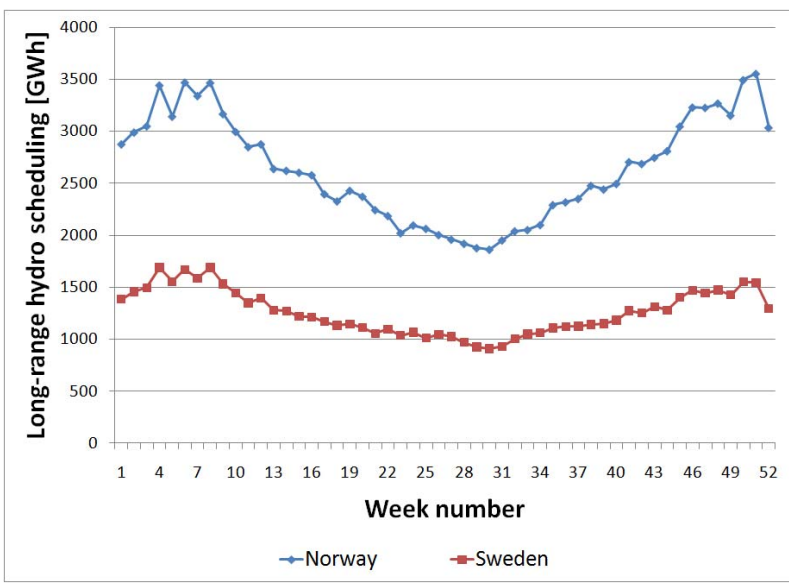

Fig. 2 Long-range hydro scheduling for Norway and Sweden [14]

Scenario B ("most likely" scenario) from the System Adequacy Forecast 2011-2025 report (SAF) from ENTSO-E [5] was used as a reference for sizing the conventional generation parks of each country per technology and also for scaling historical load series from 2011 for the year 2030. One exception is Germany, for which the recently announced nuclear shut-down was considered, resulting in no installed nuclear capacity in Germany in the year 2030. The fuel prices were based on the World Energy Outlook 2010 [16] published by the International Energy Agency, scenario New Policies. The $\mathrm{CO}_{2}$ price is taken from the same scenario and it is 46 Euro/ton $\mathrm{CO}_{2}$.

To ensure a uniform model, combined heat and power plants were not specifically modeled as data availability for such modeling was only available for the Netherlands. Instead of this, heat delivery obligations were translated in minimum generation obligations. Assumptions of minimum operating requirements were made for thermal and nuclear power plants. Moreover, it was assumed that in order to accommodate more RES the conventional generating park will be more flexible than at present, meaning that the minimum output requirements for some conventional thermal power plants were reduced to a total of $27.1 \%$ of the system's minimum load. Furthermore, the biomass units also add minimum output requirements of another $4.1 \%$ of the system's minimum load.

The Net Transfer Capacities (NTCs) between countries were based on ENTSO-E data [5] regarding the current NTC values and rough estimates of increase of the current NTCs based on the Ten-Year Network Development Plan for the next decade (2020). The power flows to the rest of the continental European system and to Ireland were neglected.

A perfect forecast was considered for both load and wind power. Within the UC-ED, it is assumed that all wind power can be curtailed, while solar and biomass generation categories are assumed to be uncurtailable. The wind energy wasted due to curtailment is reported separately in the UC-ED output. In addition to this, there might be situations where 
dumped energy is reported. Energy is dumped as a last resort when there is excess generated energy due to the flexibility constraints of the system and indicates that there is an operational problem. Dump energy is also wasted energy as it is not used. The total wasted wind energy is thus the sum of curtailed and dump wind energy.

The scenarios for wind and solar power are described in the following subsections.

\section{1) Wind power scenario}

The installed capacities for onshore wind power per country were taken from the TradeWind high wind scenario [11] for Denmark and from the Offshore Grid project for the rest of the countries [16], and for the offshore wind power from the offshore wind from the Global Offshore Wind Portal [17]. The resulting capacities are illustrated in Table I.

TABLE I SCENARIO OF INSTALLED WIND CAPACITIES FOR 2030
\begin{tabular}{|c|c|c|c|}
\hline Country & $\begin{array}{c}\text { Country } \\
\text { Prefix }\end{array}$ & $\begin{array}{c}\text { Wind onshore } \\
{[\mathbf{G W}]}\end{array}$ & $\begin{array}{c}\text { Wind offshore } \\
{[\mathbf{G W}]}\end{array}$ \\
\hline Belgium & BE & 2.5 & 3.8 \\
\hline Denmark & DK & 4.7 & 3.8 \\
\hline France & FR & 38 & 7 \\
\hline Germany & DE & 47 & 31.6 \\
\hline Great Britain & GB & 19.4 & 43 \\
\hline Netherlands & NL & 6 & 10.3 \\
\hline Norway & NO & 5.8 & 11.9 \\
\hline Sweden & SW & 7 & 7.5 \\
\hline \hline Totals & - & $\mathbf{1 3 0 . 4}$ & $\mathbf{1 1 8 . 8}$ \\
\hline
\end{tabular}

For making the wind power-time series some important aspects were considered: hub height, turbine type, decay length, locations and capacities of wind farms and wind speed-time series. The hub height was chosen to be $90 \mathrm{~m}$ for both onshore and offshore wind farms. For onshore farms only one type of turbine was used and for offshore two types of turbines were used, old and new. Availability factors of 0.95 for offshore and 0.98 for onshore wind turbines were considered. The normalized turbine power-curves are illustrated in Fig. 3. A multi-turbine approach [20] was used for each considered location with a wind speed correlation decay length of $723 \mathrm{~km}$ for onshore and of $500 \mathrm{~km}$ for offshore locations.

The wind-speed time series at $90 \mathrm{~m}$ height above ground level for the year 2007 (a medium wind year) are based on a meso-scale regional re-analysis model with a grid of 9x9 km (see Acknowledgements). The locations of the onshore wind farms were considered as per 20 September 2011 and were taken for Germany from [18] and for the rest of the countries from [19], and the capacities were scaled up. For offshore wind farms, locations and capacities for current and future wind farms available at [17] were used. For each location the closest point in the meso-scale model was taken, and the data was aggregated per found coordinates. The locations used for making the wind power-time series are shown in Fig. 4.

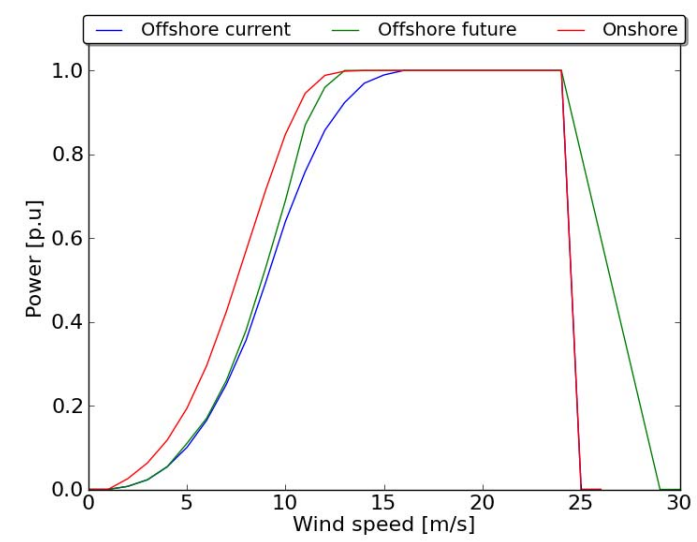

Fig. 3 Normalized power curves for the used wind turbines

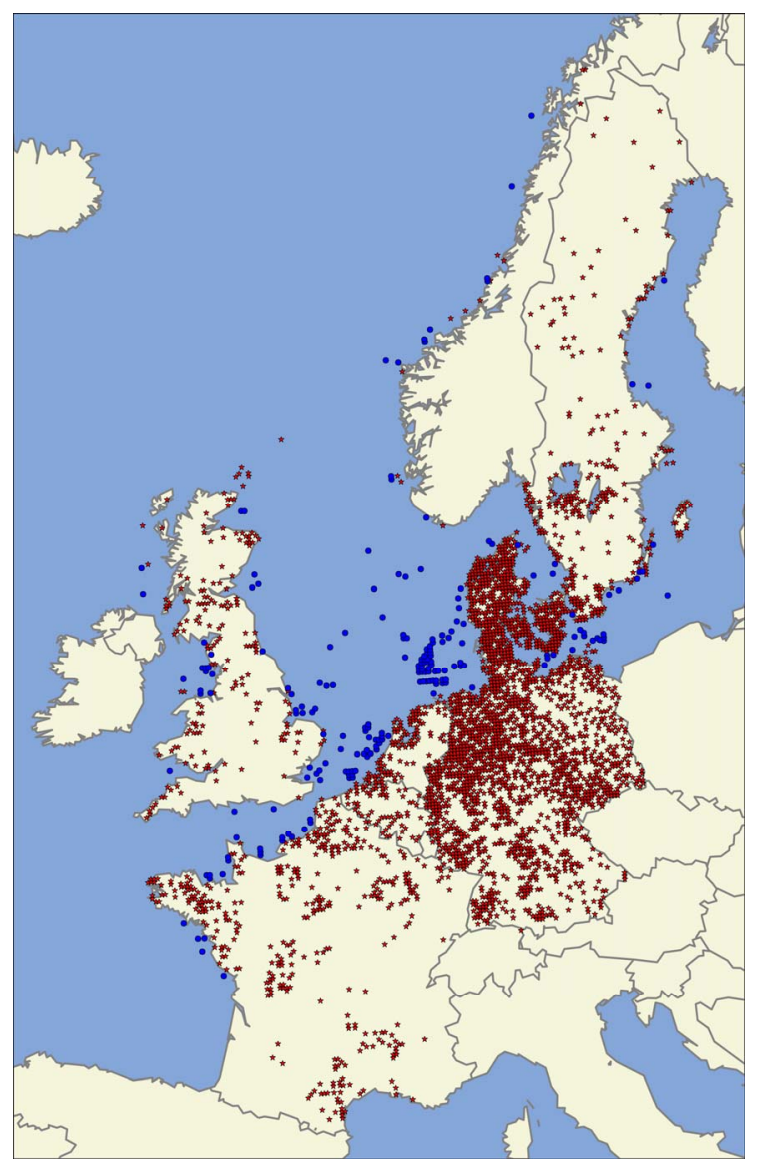

Fig. 4 Wind-speed time series found locations: blue dot- offshore, red staronshore

\section{2) Solar power scenario}

For developing the solar-power time series less locations for radiation time-series were used (Fig. 5) in comparison to the wind-speed time series, due to data availability. Solar power-time series were developed for Germany and for France. The installed capacities in 2030 per country are 13 $\mathrm{GW}_{\text {peak }}$ for France [5] and $66 \mathrm{GW}_{\text {peak }}$ for Germany (German government's targets for 2030). 


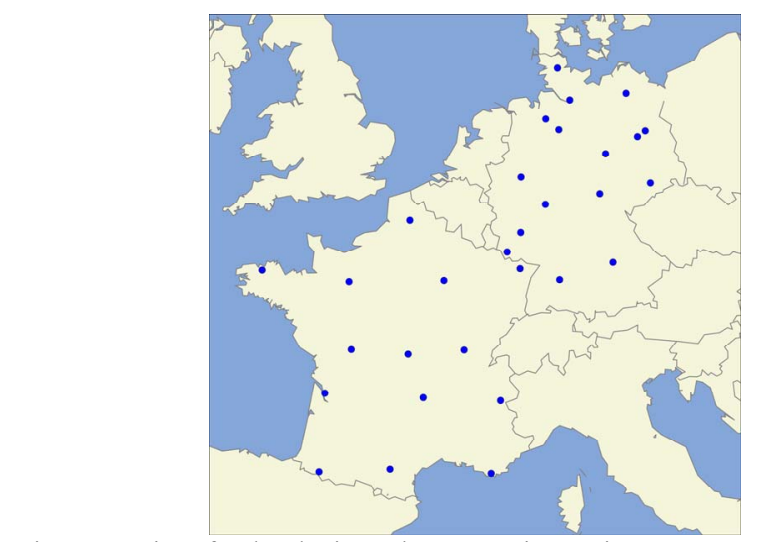

Fig. 5 Locations for developing solar power-time series

The geographical distribution of the installed capacities was done as it follows:

- For Germany: detailed data regarding the current installed capacities per postal code obtained from [18] as per 20 September 2011, was aggregated per postal code zone and ultimately per federal state. Then the increase up to $66 \mathrm{GW}$ was done proportional to the product of the normalized surface per federal state and the normalized population density per federal state. Hence, in the states with both high surface and high population density the increase is higher. For each state a location was considered, resulting in a total of 16 locations. Data regarding the federal states geographical information as well as postal codes was obtained from [21].

- For France: a share of $30 \%$ of the total capacity in the Northern half of the country and of $70 \%$ in the Southern half of the country were assumed. These shares were distributed equally between the considered locations (14 in total).

Global radiation for the year 2005 was obtained from [22] for all the locations. It was assumed that all solar modules are crystalline silicon photovoltaic modules which are inclined at a fixed optimum angle. The optimum angle $\beta$ is dependent on the latitude of the installation and was calculated as in [23].For the calculation of the solar power production the method described in [24] was used. The power output was computed taking into account the global inclined radiation, and temperature and radiation-dependent module efficiency.

As a source for the ambient temperature data from a mesoscale regional re-analysis model (see Acknowledgements) was used for all the locations. The maximum available power reaches almost $95 \%$ of the total peak capacity, which is an overestimation due to input data limitations. After comparing the solar generation profiles in terms of daily/seasonal variability and average energy content with the ones from [25], the quality of the time-series appears reasonable. Moreover, the peak overestimation is challenging as more solar generation has to be absorbed by the system. In order to account for this overestimation, also a case with a lower penetration level of solar will be considered. In Fig. 6 the total German solar and wind power-time series for a winter week and a summer week are illustrated. The seasonal and sometimes daily complementarity of solar and wind power availability can be noticed.

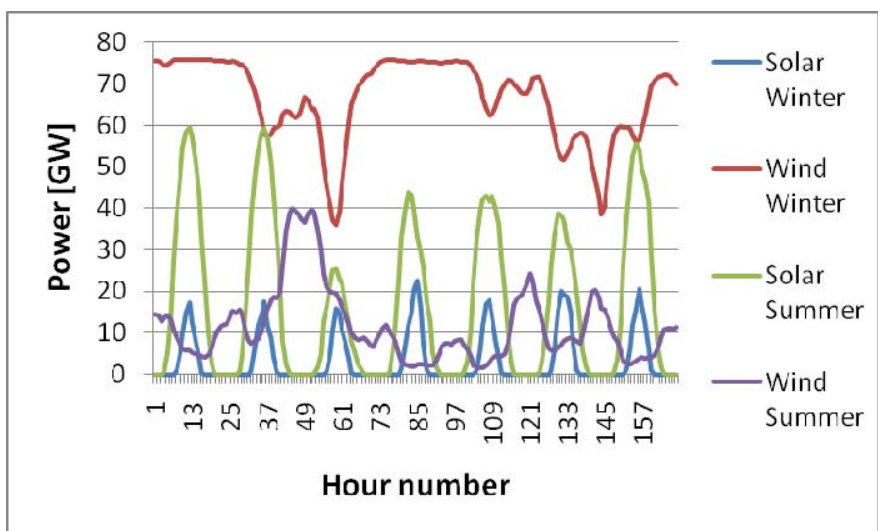

Fig. 6 Solar and wind power-time series for Germany: winter week and summer week

\section{B. Simulation Cases}

In order to analyze the impact of large-scale RES in NorthWestern Europe, a base case and some sensitivity scenarios were performed. All the information presented in Section II A constitutes the base case. In addition, the sensitivity scenarios performed are shown in Table II.

TABLE II SENSITIVITY SCENARIOS
\begin{tabular}{|c|c|l|}
\hline No & Scenario & \multicolumn{1}{c|}{ Description } \\
\hline 1 & LF & less flexible generation park \\
\hline 2 & COP & $\begin{array}{l}\text { copperplate (unlimited inter-area } \\
\text { capacities) }\end{array}$ \\
\hline 3 & C 37 & reduced $\mathrm{CO}_{2}$ price, 37 Euro/ton $\mathrm{CO}_{2}$ \\
\hline 4 & C 55 & increased $\mathrm{CO}_{2}$ price, 55 Euro/ton $\mathrm{CO}_{2}$ \\
\hline 5 & DY & dry year Norway $(105 \mathrm{TWh})$ \\
\hline 6 & LS & less solar $(50$ GW DE, $10 \mathrm{GW}$ FR) \\
\hline 7 & LWFR & less wind FR onshore $(28 \mathrm{GW})$ \\
\hline 8 & LWGB & less wind GB onshore $(12 \mathrm{GW})$ \\
\hline 9 & LWDE & less wind DE onshore $(37 \mathrm{GW})$ \\
\hline 10 & NCDEon & no wind curtailment DE onshore \\
\hline 11 & NCDE & no wind curtailment DE \\
\hline
\end{tabular}

\section{RESULTS}

Unit commitment-economic dispatch simulations were run for the base case and all sensitivity scenarios introduced in Section III B, Table II. The main results and a sensitivity analysis relative to the base case will be presented in this section.

\section{A. The Base Case}

Table III illustrates the generated energy per technology type in North-Western Europe. It can be noticed that the wind production sums up at $30 \%$ of the total generated energy (in line with EWEA's forecast), and all together the RES (biomass, solar and wind) constitute about $37 \%$ of the whole generation mix. If hydro is also added, the total percentage of clean energy production is almost $54 \%$. Then nuclear plants deliver $23.6 \%$ of the energy share, and the rest of $22.4 \%$ is represented by fossil-fuel generated energy. 
TABLE III BASE CASE: GENERATED ENERGY PER TECHNOLOGY

\begin{tabular}{|c|r|r|}
\hline Technology & \multicolumn{1}{|c|}{$\begin{array}{c}\text { Generated energy } \\
\text { [TWh] }\end{array}$} & $\begin{array}{c}\text { \% } \\
\text { total demand }\end{array}$ \\
\hline Biomass & 52.56 & 2.43 \\
\hline Coal & 179.75 & 8.31 \\
\hline Gas & 221.67 & 10.25 \\
\hline Hydro & 356.1 & 16.47 \\
\hline Lignite & 83.7 & 3.87 \\
\hline Mix fuel & 0.94 & 0.04 \\
\hline Nuclear & 510.7 & 23.62 \\
\hline Oil & 0.94 & 0.04 \\
\hline Solar & 108.95 & 5.04 \\
\hline Wind onshore & 358.53 & 16.58 \\
\hline Wind offshore & 288.48 & 13.34 \\
\hline \hline System & $\mathbf{2 1 6 2 . 3 1}$ & $\mathbf{1 0 0}$ \\
\hline
\end{tabular}

Table IV shows other main results of the UC-ED base case simulation. It can be noticed that the wasted wind energy (because of system and interconnection constraints) is very high, $134.3 \mathrm{TWh}$, representing $17.2 \%$ of the total available wind energy of 781.3 TWh. Moreover, Fig. 7 shows the share of wasted wind for each country. It can be noticed that Germany and Great Britain have the most wasted wind energy, these countries having also the highest installed capacity of wind. Next is Norway with also a large share of wasted wind energy, explainable by the hydro-wind cost competition and Norway's limited interconnection capacity. It is interesting to note that in France, even though the installed wind power is almost $45 \mathrm{GW}$, there is very little wasted wind energy. There still are some flexibility problems in the system as there $0.5 \mathrm{TWh}$ of dump energy and $0.2 \mathrm{TWh}$ of energy not served. This means that the system -- even though able to integrate almost all available solar energy -- still faces some operational problems due to inflexible generating units and transmission constraints.

TABLE IV UC-ED RESULTS FOR THE BASE CASE

\begin{tabular}{|l|c|r|}
\hline Pump Storage Load & {$[\mathrm{TWh}]$} & 19.6 \\
\hline Wasted Wind & {$[\mathrm{TWh}]$} & 134.3 \\
\hline $\mathrm{CO}_{2}$ Emissions & {$[\mathrm{kton}]$} & 337771 \\
\hline $\mathrm{CO}_{2}$ Cost & [Mil Euro] & 15537 \\
\hline Fuel Cost & [Mil Euro] & 29365.6 \\
\hline Total System Operating Cost & [Mil Euro] & 53563 \\
\hline
\end{tabular}

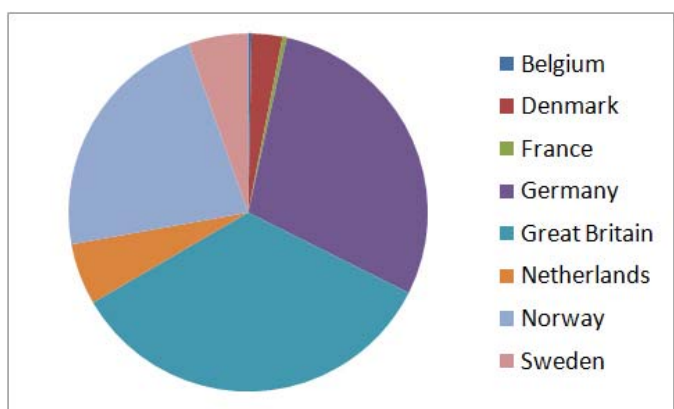

Fig. 7 Base case: wasted wind energy per country (total 134.31 TWh)

Fig. 8 illustrates the net exchanges for the base case. In our future scenario, Norway and France are the main exporters, while Belgium and Germany are the main importers.

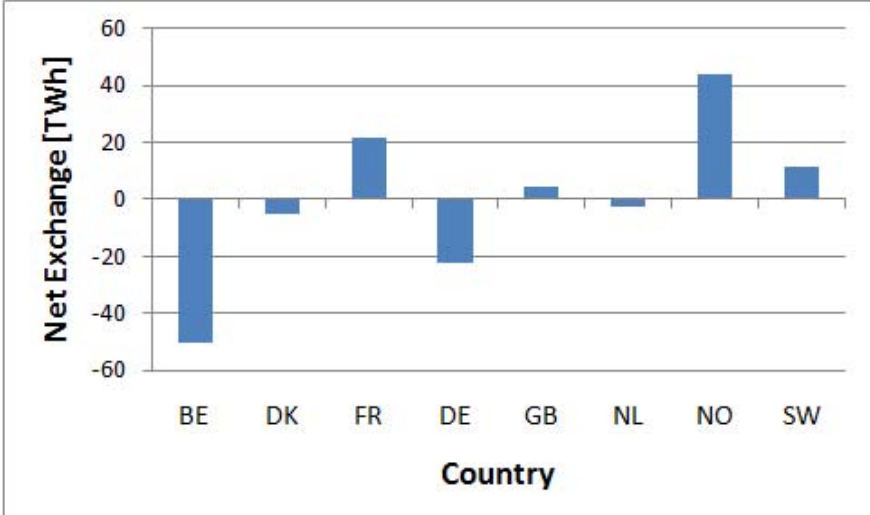

Fig. 8 Base case net exchanges (export-import)

\section{B. Sensitivity analyses}

In this section a comparison for all the sensitivity scenarios will be presented. The most important changes in the system due to a certain factor will be emphasized.

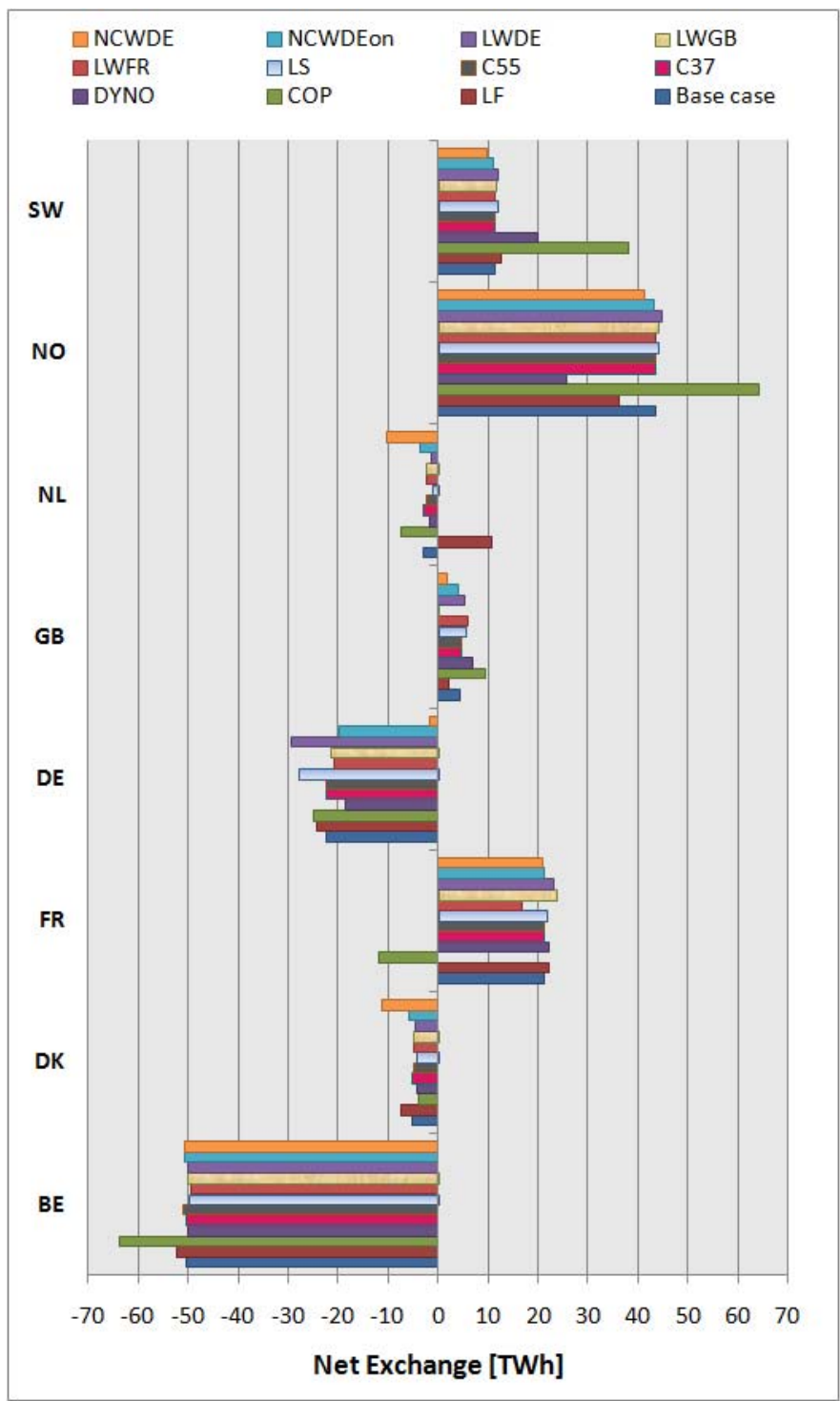

Fig. 9 Net exchange comparison for various scenarios, positive $=$ net export, negative $=$ net import 
Table $\mathrm{V}$ shows the variation of the UC-ED results for the sensitivity scenarios relative to the base case from Table IV, and Fig. 9 illustrates a comparison of the net exchanges for the base case and all the sensitivity scenarios. It can be noticed that the scenarios having the highest impact on the system in general are the Less Flexible Generation Park (LF) and the Copperplate (COP) scenarios. The $\mathrm{CO}_{2}$ price scenarios $\mathrm{C} 37$ and $\mathrm{C} 55$ affect the system operating cost, while Dry Year Norway (DYNO) reduces the wasted wind.

Table V Variation Of the UC-ED Results for the Sensitivity Scenarios Relative to the Base CASE. Notable Results ARE HIGHLIGHTED

\begin{tabular}{|c|c|c|c|c|c|c|}
\hline \multirow[b]{2}{*}{ Scenario } & \multicolumn{6}{|c|}{ Variation (increase) [\%] of the base case } \\
\hline & $\begin{array}{l}\text { Pump } \\
\text { Storage } \\
\text { Load } \\
\end{array}$ & $\begin{array}{l}\text { Wasted } \\
\text { Wind }\end{array}$ & $\mathrm{CO}_{2}$ & $\begin{array}{l}\mathrm{CO}_{2} \\
\mathrm{Cost}\end{array}$ & $\begin{array}{l}\text { Fuel } \\
\text { Cost }\end{array}$ & $\begin{array}{l}\text { Total } \\
\text { Cost }\end{array}$ \\
\hline $\mathbf{L F}$ & 10.19 & 58.35 & 9.84 & 9.84 & 17.62 & 12.48 \\
\hline COP & 56.15 & -49.71 & -10.56 & -10.56 & -8.46 & -8.35 \\
\hline DY & 12.67 & -16.34 & 0.65 & 0.65 & 0.56 & 0.66 \\
\hline C37 & 7.34 & 0.07 & 0.68 & -19 & -0.37 & -5.73 \\
\hline C55 & -2.13 & -0.08 & -1.08 & 18.26 & 0.71 & 5.75 \\
\hline $\mathbf{L S}$ & -1.24 & -4.56 & 2.38 & 2.38 & 2.06 & 2.05 \\
\hline LWFR & 2.13 & -1.11 & 0.75 & 0.75 & 1.27 & 1.36 \\
\hline LWGB & 0.63 & -11.25 & 2.18 & 2.18 & 1.82 & 1.88 \\
\hline LWDE & 1.86 & -12.93 & 2.89 & 2.89 & 1.71 & 2.02 \\
\hline NCWDEon & 0.64 & -0.208 & 0.31 & 0.31 & -0.45 & -0.21 \\
\hline NCWDE & 2.55 & -0.19 & 0.29 & 0.29 & -0.45 & -0.22 \\
\hline
\end{tabular}

\section{1) Sensitivity to generation park flexibility}

It can be noticed that the factor that mostly affects the system is its flexibility. In scenario LF, the minimum output requirements of most of the conventional thermal generating units are double the ones in the base case, summing up to $52.4 \%$ of the system's minimum load. Having a less flexible system increases the total system operating cost by $12.5 \%$, an equivalent of 6678 mil Euro per year. Moreover, the wasted wind energy increases by $58.4 \%$, resulting in a wasted wind energy total of $27.2 \%$ of the available wind. The decrease of wind production that can be integrated can be seen also in Fig. 10 , together with an increase of nuclear, lignite and gas stations, and decrease of coal generation. Netherlands (having many gas-fired plants) becomes from a net importer, a net exporter (Fig. 9). The not served energy is the same as in the base case, but the dump energy increases to $1.7 \mathrm{TWh}$. This means that the operational problems of the system are increased.

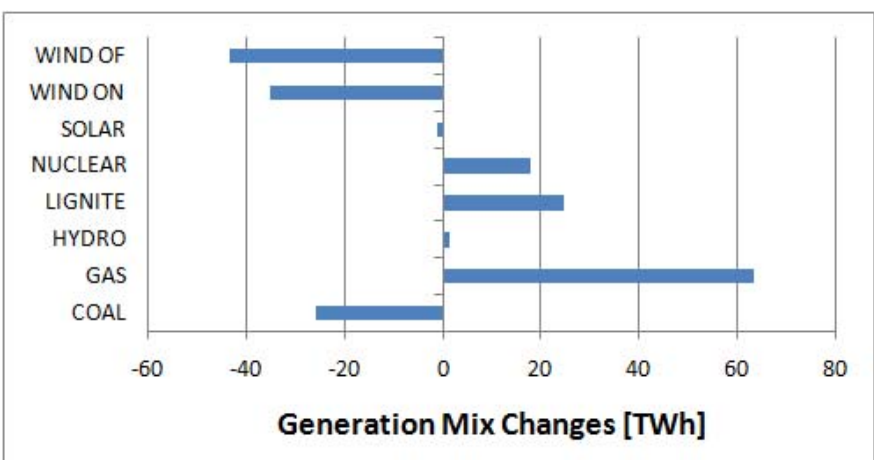

Fig. 10 Less flexible generation park scenario: generation mix changes relative to the base case

\section{2) Sensitivity to interconnection capacity: the value of} copperplate

The copperplate (COP) scenario also brings some changes. The total system operating cost decreases with $8.4 \%$ and the wasted wind energy is reduced by almost $49.7 \%$, resulting in $8.7 \%$ unused wind energy from the total available wind energy. Dump energy and energy not served values are zero in this scenario, as the flexibility of the system is increased by relaxing the inter-area constraints. In Fig. 11 it can be seen that both hydro and wind production increase, while thermal power plants decrease their production share.

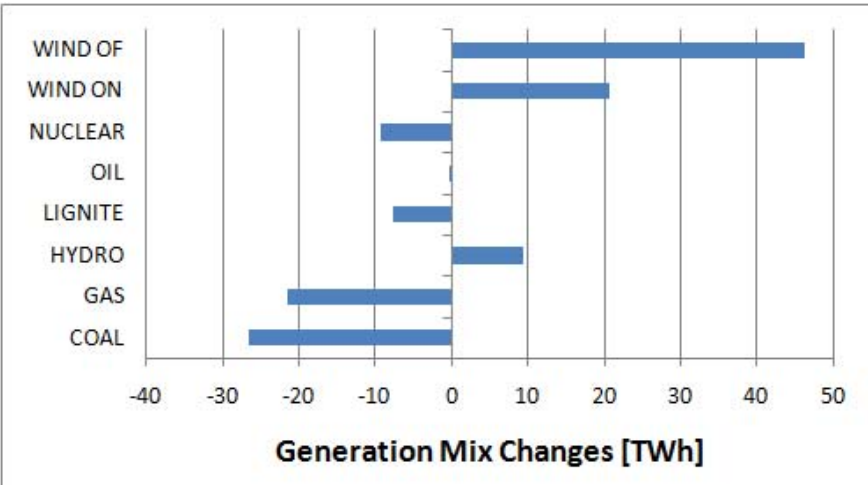

Fig. 11 Copperplate scenario: generation mix changes relative to the base case

The copperplate facilitates the trade between countries. Norway and Sweden increase dramatically their exports. Germany and Great Britain increase both their exports and imports, while France, Belgium, and Netherlands increase their imports visibly (see Fig. 9). Denmark decreases both its imports and exports. The usage of Pump Storage Facilities is also increased by more than $50 \%$.

\section{3) Sensitivity to hydro energy availability in Norway}

The lower hydro energy availability does not have a big impact on the system. Mainly, the hydro energy is replaced with wind (mostly from Norway) and thermal units (mostly nuclear) Fig. 12.

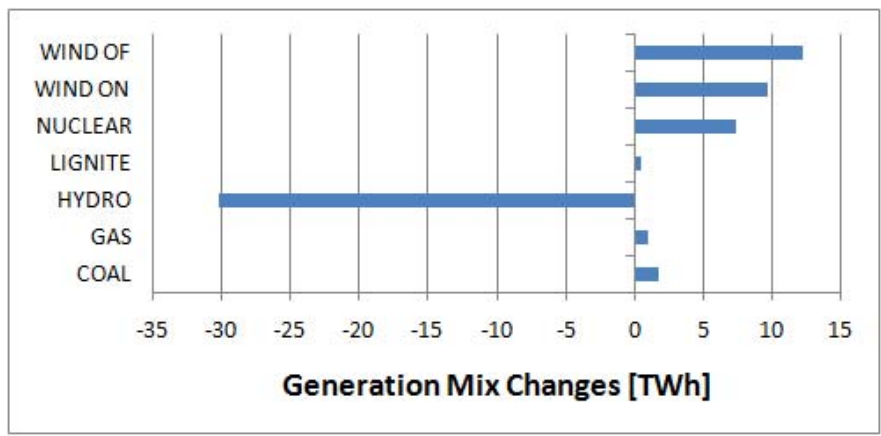

Fig. 12 Dry year in Norway: generation mix changes relative to the base case

\section{4) Sensitivity to $\mathrm{CO}_{2}$ price}

The sensitivity of the generation mix to $\mathrm{CO}_{2}$ price is very low. At a variation of -9 Euro/ton $\mathrm{CO}_{2}(\mathrm{C} 37)$ and +9 Euro/ton $\mathrm{CO}_{2}$ (C 55) the changes in the production shares are very small, shifting (as expected) from coal and lignite to gas and hydro in C55 and the other way round for C37. 


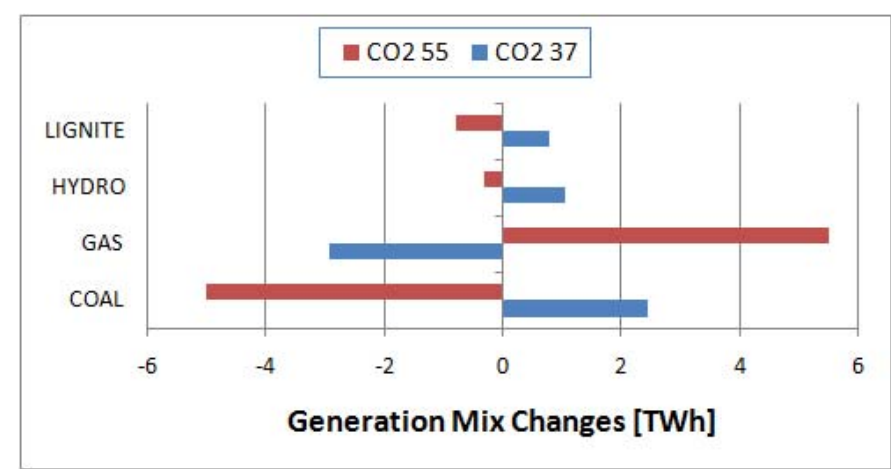

Fig. $13 \mathrm{CO}_{2}$ price scenarios: generation mix changes relative to the base case

From an economic point of view, the total operating cost is influenced by the $\mathrm{CO}_{2}$ price variation. In the $\mathrm{C} 37$ scenario, total cost decreases by $5.7 \%$ while in the C55 it increases with the same percentage. These variations are mostly due to a large extent to changes in the total $\mathrm{CO}_{2}$ operating cost but also to the fuel operating cost changes (since both these costs are part of the objective function of the UC-ED optimization engine).

\section{5) Sensitivity to RES penetration level}

As the RES penetration is already high, 3 sensitivity scenarios to lower wind power penetration and 1 to lower solar power penetration were investigated. Concerning the wind penetration level, it can be noticed from Fig. 14 that the scenarios with less wind onshore all cause a shift in generation towards offshore wind and thermal power plants, also causing a slight increase in total production cost of $1-2 \%$. Moreover as summarized previously in Table $\mathrm{V}$, the wasted wind energy decreases, but the decrease is proportional to the decrease in wind capacity.

The scenario with less installed solar power, causes also an increase of $2 \%$ of the total operating cost, that is due to a shift of generation towards wind onshore (hence with almost $5 \%$ less wasted wind energy), and thermal power plants. The net exchanges profiles stay almost the same as in the base case.

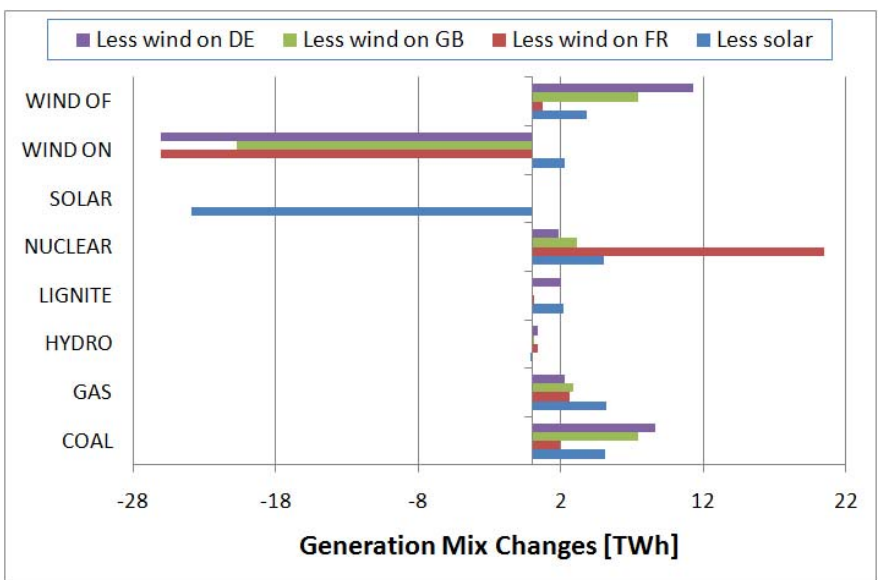

Fig. 14 Less RES scenarios: generation mix changes

\section{6) Sensitivity to curtailment strategy in Germany}

The sensitivity to German curtailment strategy is very low. Whether the curtailment is not allowed for both German onshore and offshore wind farms or only for onshore farms, there are small generation shifts due to the changes in the hourly optima. Even though the curtailments are reduced, wind power is still wasted in Germany, and it appears as a high increase in dump energy. This signals the fact that the system is constrained and has reached a limit in RES integration.

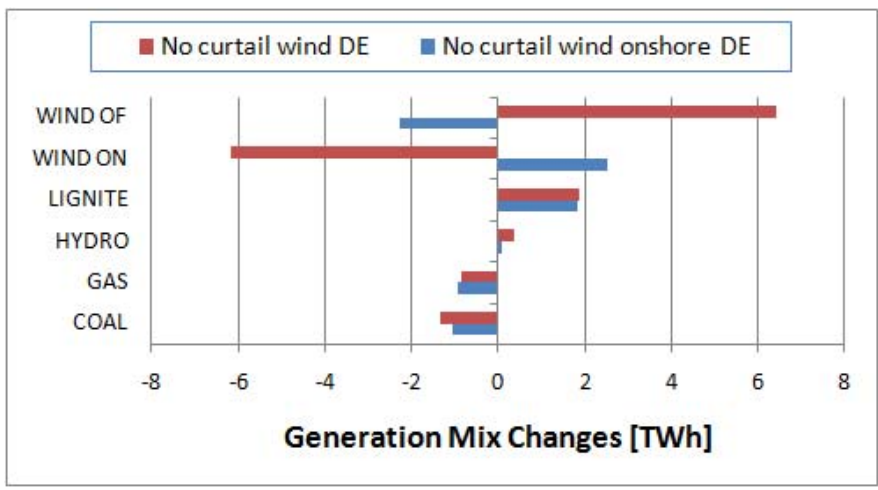

Fig. 15 Curtailment strategy DE scenarios: generation mix changes relative to the base case

\section{CONCLUSIONS AND RECOMMENDATIONS}

This work assessed the consequences of large-scale solar and wind power integration into the North Western European interconnected system for a 2030 scenario of load and generation. To this purpose, detailed chronological and correlated wind power and solar power time series were developed. Unit commitment and economic dispatch simulations were run for a base case and a number of sensitivity scenarios. Solar and biomass plants were assumed uncurtailable. A conservative assumption was made for the base case where interconnection capacities were kept at the 2020 values. The impact of transmission capacity was handled in the sensitivity analysis. The results show that almost all of the $79 \mathrm{GW}$ of installed solar capacity are integrated, and also $82.8 \%$ of the available wind energy generated by the $249 \mathrm{GW}$ installed wind capacity is used. Wind energy solely, provides $30 \%$ of the system's demand. Wind, solar, biomass and hydro power plants deliver $53.9 \%$ of the total energy demand, together with nuclear production of $23.6 \%$ and only $22.5 \%$ fossil-fuel generated energy. However $17.2 \%$ of the total available wind energy is wasted (because of system and interconnection constraints); that is about $6 \%$ of the total system demand. Norway and Great Britain are the biggest net exporters while Belgium and Germany are the biggest net importers. Even in the base case, where all wind is assumed curtailable, the system is not flexible enough, as the model outcomes indicate operational problems.

The sensitivity analysis pointed out some important aspects. The main factor influencing RES integration proved to be the flexibility of the generation system. By increasing by half the must run requirements of most of the thermal power plants, the total system operating cost increased by $12.5 \%$, and the 
resulting wasted wind energy ratio relative to the total available wind energy grew to $27.2 \%$ (or $9.8 \%$ of demand). This means that future power systems should become more flexible and give a higher credit to RES generation.

Interconnection capacity is also an important factor for RES integration. Unlimited interconnection capacities reduce system operating cost by $8.4 \%$ and decrease the unused wind energy to $8.7 \%$ of the total available wind energy or roughly $3 \%$ of demand while operational problems are also eliminated. Exports from Norway and Sweden increased dramatically.

Hydro energy availability in Norway has a small impact on the system, as hydro is replaced by wind. Moreover variations of $\pm 5 \%$ of the $\mathrm{CO}_{2}$ price also have almost no influence on the generation mix, but they affect the total system operating cost. It may be that a very high increase of $\mathrm{CO}_{2}$ price would make a difference also for the generation mix. Wasted wind was not sensitive to the curtailment strategy in Germany. The wasted wind values stay almost unchanged, since dump wind energy increases. Note that demand side management was not considered in this work.

For gaining a better understanding of the problems of integrating large-scale RES, future research should be dedicated to analyzing from the operational point of view the most interesting scenarios variants highlighted in this paper.

\section{ACKNOWLEDGMENT}

Meteorological data have been derived based on a mesoscale regional re-analysis model by Sander + Partner, Switzerland.

\section{REFERENCES}

[1] Green Paper - A European Strategy for Sustainable, Competitive and Secure Energy, EU, 2006

[2] Promotion of the Use of Energy from Renewable Sources, EU, 2009.

[3] EWEA, "Powering Europe: wind energy and the electricity grid," 2010.

[4] EWEA, "Wind in power. 2010 European statistics," 2011.

[5] ENTSO-E, http://www.entsoe.eu/

[6] N. S. C. O. G. Initiative, "Memorandum of Understanding," ed. http://ec.europa.eu/energy/renewables/grid/doc/north_sea_countries_o ffshore grid initiative mou.pdf, 2010.

[7] EC COM(2011) 112 final, A Roadmap for moving to a competitive low carbon economy in 2050

[8] P. Menna et al, European Photovoltaic Actions and Programmes2011”, EU PVSEEC, Hamburg, 2011

[9] EU. ( 2011). Winspeed EU-IEE project. Available: http://www.windspeed.eu

[10] OFFSHORE GRID project, http://www.offshoregrid.eu/

[11] TradeWind project, http://www.trade-wind.eu/

[12] Operation Simulation Associates, Inc. PowrSym3 User's Manual v361d2. Technical report, OSA

[13] B.C. Ummels, "Power System Operation with Large-Scale Wind Power in Liberalised Environments", PhD thesis, TU Delft, 2008

[14] K. Ntotas, M. Gibescu. W.L. Kling, B.C. Ummels, E. Pelgrum, "Flexible international exchanges: a possible solution for large-scale wind power integration", PowerTech, 2009 IEEE Bucharest

[15] B.C.Ummels," "System Operation with Large-Scale Wind Power in Liberalised Environments", $\mathrm{PhD}$ thesis, Delft University of Technology, The Netherlands, 2008

[16] International Energy Agency, "World Energy Outlook 2010", 2010. Available online at: http://www.worldenergyoutlook.org

[17] Global Offshore Wind Portal, http://www.4coffshore.com/
[18] http://www.energymap.info/

[19] http://www.thewindpower.net/

[20] M. Gibescu, A.J. Brand, W.L. Kling, "Estimation of Variability and Predictability of Large-scale Wind Energy in The Netherlands", Wiley Wind Energy 2009, vol 12, pag 241-260.

[21] www.wikipedia.com

[22] www.soda.com

[23] www.macslab.com/optsolar.html

[24] T. Huld, M. Suri, E.D. Dunlop, "Geographical Variation of the Conversion Efficiency of Crystalline Silicon Photovoltaic Modules in Europe", journal Progress in Photovoltaics: Research and Applications 2008, vol 16, pag 595-607

[25] http://www.sma.de

\section{BIOGRAPHIES}

Ana Roxana Ciupuliga received the Dipl.Eng. in Electrical Power Engineering from the University Politehnica, Bucharest, Romania in 2008. Since October 2008 she has been with the Electrical Power Systems group at Delft University of Technology, Delft, The Netherlands, where she is working toward her Ph.D. degree. Her present research interests include transmission expansion planning for large-scale wind integration, sustainability assessment for transmission projects and approval procedures for transmission projects.

Madeleine Gibescu received the Dipl.Eng. in Power Engineering from the University Politehnica, Bucharest, Romania in 1993 and her MSEE and Ph.D degrees from the University of Washington, Seattle, WA, U.S. in 1995 and 2003, respectively. She has worked as a Research Engineer for ClearSight Systems and as a Power Systems Engineer for the AREVA T\&D Corporation of Bellevue, WA, U.S. She is currently an Assistant Professor with the Electrical Power Systems group at the Delft University of Technology, The Netherlands.

Engbert Pelgrum has received his B.Sc. Degree in Electrical Engineering from the Technical College of Zwolle (the Netherlands). He is with the Regulation \& Grid Economy $\mathrm{n}$ department of TenneT B.V., the Dutch Transmission System Operator. He is responsible for the development of European power market and transmission system simulation models, used in the field of system development and security of supply, as well as for analyses related to the medium and long term development of the Dutch and European power systems. He has over 20 years of experience in the area of chronological system modeling and power system operation and planning for the Dutch and foreign generation and transmission systems.

Mart A.M.M. van der Meijden (M'10) received his M.Sc. degree in Electrical Engineering from the Technical University of Eindhoven, the Netherlands, in 1981. From 1982 to 1988, he worked with ASEA/ABB in the field of process automation. The last 20 years, he has been working with different Dutch energy companies. He has been involved in development initiatives as grid technology innovation, implementation of sustainable energy, development of new organizational strategies, and implementation of asset management. $\mathrm{He}$ has joined and chaired different national and international expert groups. Since 2003, he is working with TenneT TSO. He is innovation manager and responsible for the development of the TenneT Vision 2030. In 2011, he became a part-time professor in the Department of Electrical Sustainable Energy, Faculty of Electrical Engineering Mathematics, and Computer Science, Delft University of Technology, Delft, The Netherlands.

Wil L. Kling (M'95) received the M.Sc. degree in electrical engineering from the Eindhoven University of Technology, the Netherlands, in 1978. From 1978 to 1983 he worked with Kema, from 1983 to 1998 with Sep and since then up till the end of 2008 he was with TenneT, the Dutch Transmission System Operator, as senior engineer for network planning and network strategy. From 1993 up till 2010 he was a part-time Professor at the Delft University of Technology and since 2000 also at the Eindhoven University of Technology, The Netherlands. From December 2008 he is appointed as a full Professor and chair of Electrical Energy Systems group at the Eindhoven University of Technology. He is leading research programs on distributed generation, integration of wind power, network concepts and reliability issues. Prof. Kling is involved in scientific organizations such as Cigré and IEEE. He is the Dutch Representative in Study Committee C6 Distribution Systems and Dispersed Generation and the Administrative Council of Cigré. 